\title{
Geographical Patterns in Biodiversity: Towards an Integration of Concepts and Methods from Genes to Species Diversity
}

\author{
José Alexandre Felizola Diniz-Filho \& Luis Mauricio Bini
}

Departamento de Ecologia, Instituto de Ciências Biológicas, Universidade Federal de Goiás - UFG, Goiânia, GO, Brazil

\begin{abstract}
Definitions of Biodiversity that encompass multiple levels of the biological hierarchy are common and fulfill theoretical and conservation expectations. However, these definitions are usually not fully operational because these levels are usually analyzed independently. We understand that the difficulties in integrating concepts and methods for distinct "Fundamental Biodiversity Units" (FBUs) for analyses, including genes, haplotypes or neutral molecular variants, species, biomes or ecosystem, arise both because of operational and conceptual difficulties in dealing with the evolutionary continuum and because of 'sociological' issues regarding how different research traditions in Ecology and Evolutionary Biology deal with these different FBUs. Here we explore some common patterns of geographic variation in FBUs at different hierarchical levels, starting from the conceptual view by which evolution give rises to a continuum of biodiversity. We seek for an integrated methodological and conceptual framework to study FBUs, searching for the relationships and commonalities of concepts and methods traditionally developed to evaluate patterns and processes at a given level of the biological hierarchy. We point out several cases where conceptual and theoretical advances have been made by using an integrated perspective based for FBUs, for the analysis of broad-scale gradients in richness, distance decay similarity and systematic conservation planning. We conclude by stating that the recognition of an integrated approach that takes the evolutionary continuum into account may be an important step to mitigate biodiversity loss.
\end{abstract}

Key words: Richness Gradients, Distance-Decay, Systematic Conservation Planning, Species Diversity, Spatial Analyses.

\section{Introduction}

Biodiversity has been defined as

"...the variability among living organisms from all sources including, inter alia, terrestrial, marine and other aquatic ecosystems and the ecological complexes of which they are part; this includes diversity within species, between species and of ecosystems" (CBD, 1992, article 2).

Also, Gaston (1996, p. 1) presents several variants of the term "biodiversity" around the idea that

"biodiversity is often defined as the variety of all forms of life, from genes to species, through to the broad scale of ecosystems..."

Although this kind of definition has been widely used and propagated, fulfilling theoretical and conservation expectations, comprehensive, all-inclusive (or integrated) biodiversity analyses remain mostly elusive. We believe these definitions are not fully operational because, although the idea of diversity at multiple levels of the biological hierarchy is important, these levels are usually analyzed

\footnotetext{
*Send correspondence to: José Alexandre F. Diniz-Filho Departamento de Ecologia, Instituto de Ciências Biológicas, Universidade Federal de Goiás - UFG, CP 131, CEP 74001-970, Goiânia, GO, Brasil e-mail: diniz@icb.ufg.br
}

independently. As will be more fully explained below, biodiversity patterns arise by a combination of adaptive (i.e., driven by deterministic process of natural selection mediated by environment) and neutral processes, arising as part of a continuum through evolutionary time (Avise 2004). We recognize that the difficulties in integrating concepts and methods for distinct "Fundamental Biodiversity Units" (FBUs) of analyses (e.g., units that may be genes, haplotypes or neutral molecular variants, species, biomes or ecosystem, and so on) arise because of operational and conceptual difficulties in dealing with this continuum and with 'sociological' issues regarding how different research traditions in Ecology and Evolutionary Biology deal with different FBUs. Hiearchy theory of ecology deals mainly with emerging properties at distinct levels of hierarchical systems from individuals to ecosystems (see Yarrow \& Salthe 2008 for a review) and, although we recognize the importance of such boundaries and emerging properties, we believe that evolutionary dynamics can provide an integrated basis for methodological integration, as will be proposed throughout the text.

Moreover, an important issue to be explored is that biodiversity follows Tobler's (1970, p. 3) first law of geography: 
"Everything is related to everything else, but near things are more related than distant things". A comprehensive view of these space-time processes and deeper integration of concepts and methods is important for both understanding the dynamics of biodiversity and to establish better strategies for its conservation under the current biodiversity crisis (Whittaker et al. 2005; Ladle \& Whittaker 2011; Loyola et al. 2011). As a consequence of the complexity around the biodiversity concept and of research traditions, studies have generally been ad hoc, focusing on parts of the evolutionary/ hierarchical continuum (as defined by the FBUs), in which different stochastic or deterministic processes predominate. In recent years, however, the interplay between all these processes has inspired several interdisciplinary research disciplines coupling ecology, genetics and evolution, such as phylogeography (Avise 2004; 2009), community phylogenetics (Webb et al. 2002; Vamosi et al. 2009), molecular ecology (Beebee \& Rower 2004), geographical, landscape and conservation genetics (Epperson 2003; Manel et al. 2003; Storfer et al. 2010). The recent field of metagenomics, for instance, offers interesting insights into the integration of the concepts of species richness and genetic or phylogenetic diversity, and the analysis of geographical patterns of variation at broader scale can be useful for revealing how diversity is explained by different sets of ecological and evolutionary processes (e.g., Decaëns 2010; Dequiedt et al. 2011).

Most of the emerging research disciplines mentioned above deal with geographical patterns and processes (Diniz-Filho et al. 2008; Thomassen et al. 2011). In many cases, however, these new disciplines arise to solve particular problems and it is usually not emphasized how these approaches can lead to an even more integrated view of biodiversity, both conceptually and operationally. The establishment of a clear theoretical basis for this "strong integration" would allow more comprehensive analyses and interpretation of biodiversity patterns. This task would be facilitated by biodiversity and environmental data acquisition using GIS and remote sensing techniques (Graham et al. 2004; Kozak et al. 2008) and by the use of statistical analyses of geographic and evolutionary patterns with direct conservation implications (Epperson 2003; Diniz-Filho \& Telles 2002, 2006; Landeiro \& Magnusson 2011). However, we still lack the tools and the theoretical background to effectively work across the different hierarchical levels represented by FBUs, taking complex processes into account.

Here we explore some common patterns of geographic variation in biodiversity at different hierarchical levels. Starting from the conceptual view defined above, in which evolution give rises to a continuum of biodiversity at multiple hierarchical levels, we seek for an integrated methodological and conceptual framework to study FBUs. Our quest is based on the relationships and commonalities of concepts and methods traditionally developed to evaluate patterns and processes at a given level of the biological hierarchy. We claim that these concepts and methods can be "up or downscaled" across levels and, for simplicity, will focus mainly on molecular and species levels, although upscaling to other levels seems to be promising as well (e.g., Crisp et al. 2009). At a strong level of integration, we think that these concepts and tools can substantially change the way we measure and evaluate biodiversity.

\section{Biodiversity Analyses Across the Evolutionary Continuum}

\section{The origin of biodiversity and the evolutionary continuum}

As conceptual basis for a methodological integration when dealing with several FBUs, it is interesting to start by assuming a pure neutral process, in which diversity is created and driven by random events of birth, death and diversification (i.e., the balance between speciation and extinction). Under such process, the interaction among alleles and their distributions are mediated by breeding and, at a higher population level, by demographic processes. At any time, mutations occur, giving origin to closely related (in terms of structural similarity and phenotypic expression) alleles. The combination of these events will drive the dynamics of alleles across geographic space. By chance, increasing differences among individuals can lead to reproductive isolation, which allows defining units according to the classical concept of species (ignoring for a moment that other more complex ecological and behavioral processes may be involved in generating reproductive isolation). Thus, there is a clear disruption of the dynamics of alleles because reproductive isolation allows overlap in time and space without mutual interference among them. When uniparental molecular variation is considered, such as mtDNA and cpDNA, the separation between past and future events will not be directly affected by reproductive isolation - this was the basis for the emergence of phylogeography (Avise 2009). The same process will occur simultaneously across multiple lineages, giving rise, in last instance, to patterns of overlap among species in ecological communities.

Evolutionary and genealogical views allow a better understanding how biodiversity patterns arise and, under simple neutral processes, it is expected that diversity patterns will typically be spatially patterned (i.e., because of the common space-time dynamics along the continuum) (Figure 1). However, the dynamic described above is actually much more complicated, mainly because the interplay between neutral processes and other ecological and behavioral deterministic processes are mediated by environmental variation. This complexity creates deviations from the simple genealogical expectation, as not all genetic variation behaves in the same way in different environments. Indeed, natural selection and niche patterns will affect this simple dynamics at all levels and create more complex non-stochastic patterns which may be difficult to track, especially because environments and interaction among 


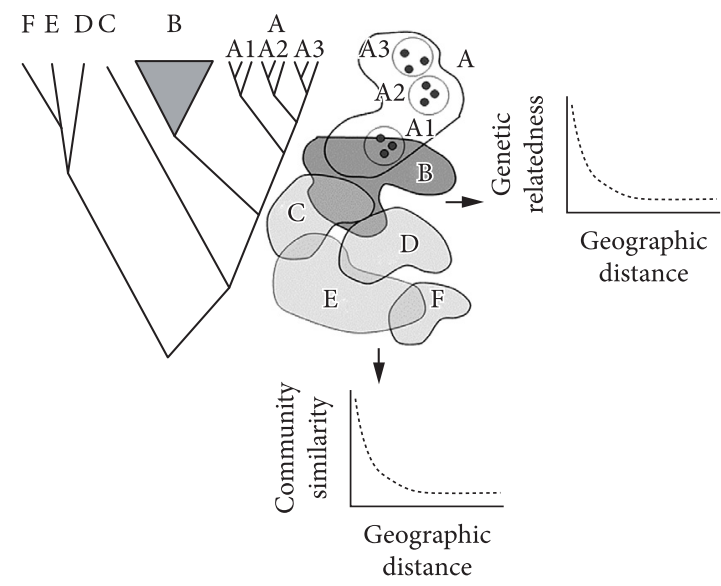

Figure 1. An scheme illustrating the origin of space-time patterns of biodiversity continuum, starting with individuals (or haplotypes) within local populations A1, A2 and A3 of the space A, and expanding to species B, C, D, E and F. Because the evolutionary dynamics is structured in geographic space, distance decay will appear for both similarity among local populations within species A and community similarity.

lineages will change through time. At higher hierarchical levels adaptive reasoning may be particularly important to explain community patterns, and the recent interest in phenotypic patterns driving species' coexistence and their ecosystem function will require a more integrated view on evolutionary dynamics driving community patterns (McLachlan \& Ladle 2011).

\section{Defining biodiversity's fundamental units}

Even basic levels of the evolutionary continuum, such as species or molecular variants, are not well understood and the definition of these more fundamental units of biodiversity is rarely free of discussion (e.g., Avise 2004). Species, for instance, are regarded as real entities and it is generally assumed that they are valid from a systematic point of view. However, establishing the magnitude of threat to biodiversity by defining and counting endangered species is, by definition, linked to the way species are defined (Mace et al. 2003). In an analogous reasoning, the advent of sophisticated molecular markers create smaller units of biological variation that are now being used as fundamental units for calculating genetic diversity. Although it is doubtless that molecular markers are powerful tools for species delimitation and are more adequate to study genetic variation within populations, using too refined markers can provide more units than necessary and is responsible, at least in part, for what has been called taxonomic inflation (Isaac et al. 2004).

The problems with defining FBUs and the view of an evolutionary continuum inspire some hard questions, such as: "do we really need to define fundamental units to measure and understand biodiversity patterns? Also, is this separation of basic units at distinct levels making even harder to have an integrated operational view of biodiversity patterns and processes"? Biodiversity metrics usually ignore that each FBU cannot be taken as an independent source of evidence about evolutionary processes as FBUs are phylogenetically related to each other, which constitutes a general space-time autocorrelation problem (Peres-Neto 2006).

Evolutionary theory and phylogenetics may give better clues towards working with continuous variation across biological levels rather than with a single, arbitrarily defined, level of that hierarchy (see below). Also, we believe that better defining and thinking about fundamental units in an operational and integrated way will probably be important to manage biodiversity in the years to come. A compromise between the recognized difficulties of taking biodiversity continuity into account and operationally establishing FBUs seems to encompass at least two overall principles: i) FBUs are only part of a continuum in geographic space and evolutionary time, and this idea should be considered by analyses and interpretations of patterns exhibited by FBUs and their combination (richness, turnover). When possible, autocorrelation-based techniques should be used to take the lack of independence among FBUs into account helping to evaluate patterns and processes (e.g., Peres-Neto 2006; Stone et al. 2011); ii) FBUs at a given hierarchical level are actually a sample of possible particles that evolved through geographical space and evolutionary time, both because of extinction processes and because of our lack of biodiversity knowledge. Although it is possible to factor in the lack of knowledge by species description curves and simulation procedures (e.g., Bini et al. 2006; Pimm et al. 2010), this is hard to do operationally. Thus, to detect patterns, infer processes and make effective conservation decisions, we must consider overall FBUs space-time dynamics rather than the particular behavior of a single FBU. To achieve this overall understanding, a critical assumption is that FBUs are randomly sampled through appropriate evolutionary, geographical or ecological dimensions.

\section{Integrated Geographical Analyses of Biodiversity Patterns and Processes}

\section{Geographic patterns of diversity and richness at multiple hierarchical levels}

The accumulation of FBUs, such as species or molecular variants, in a given spatial realm will occur by both adaptation, natural selection, and by historical stochastic events. When thinking about deterministic processes such as natural selection and adaptation, one can assume that distribution of FBUs will expand across environmentally suitable areas within a delimited geographic domain. A high diversification rate in environmentally suitable areas is also expected (e.g., Rangel \& Diniz-Filho 2005). This will of course generate a correlation between the number of FBUs and environmental gradients, but it is not trivial to disentangle adaptive and historical processes. The molecular variants usually analyzed are considered neutral 
or quasi-neutral, so the role of such deterministic process is usually considered small and broad-scale gradients in the number of molecular FUBs are unlike to arise as a response to selection (Freedman et al. 2010; Keller et al. 2011). On the other hand, when species are used as FBUs and species richness is analyzed, environmental drivers have usually considered exerting a much more important role.

Latitudinal gradients in species richness, i.e., a pattern in which tropics are richer in species than the temperate regions, have been known since the late XVII century, but up to now there is discussion regarding the relative importance of the likely processes involved in their origin and maintenance (Hawkins, 2001). In general, the strong correlations between richness and environmental variation, notably the water-energy dynamics (e.g., Hawkins et al. 2003), for different taxonomic groups suggest an important role of the current environment in the accumulation of species in the tropics. However, it is difficult to distinguish if this correlation emerges from geographic range dynamics of the current species (i.e., a "current process") or by environmentally-driven variation in the diversification rates (the balance between speciation and extinction; "historical" processes (Mittelbach et al. 2007). There are several possible combinations of speciation and extinction rates that could account for the latitudinal pattern, including higher speciation rates in the tropics due to high energy leading to higher mutations rates, or higher extinctions rates in the temperature regions due to environmental instabilities through time. Guisan \& Rahbek (2011) (see also Terribile et al. 2009) recently proposed an interesting integrated framework coupling models for species' geographic ranges and richness that may help disentangling the effects of environmental drivers at distinct levels and, consequently, to understand how other factors drive patterns.

However, the increasing recognition of the role of evolutionary dynamics in shaping these broad-scale patterns has led to an important potential of integration between evolutionary and molecular biology with ecology and biogeography. The idea is that the accumulation of species will occur not because of geographical patterns in diversification rates, but rather because tropical environments have existed for a longer time than current temperate regions. Because of the retention of ancestral states during evolution (conservatism of niches or of geographic location) the species will tend to persist in their ancestral regions and will accumulate there. According to this hypothesis, there are more species in tropical regions because most groups originated in the tropics under tropical climatic regime so they tend to be unable to disperse out of the tropics (because of niche conservatism). Simultaneously, the greater time available for speciation has led to higher species richness in the tropics for most taxa due to simple accumulation of FBUs (Wiens \& Donoghue 2004; Rangel et al. 2007). This hypothesis can be tested using different phylogenetic approaches, such as mapping richness of groups at distinct phylogenetic levels, comparing geographic patterns of clades or the statistical distribution of species' centroids in environmental niche space (Wiens \& Donoghue 2004; Hawkins et al. 2006, 2007; Diniz-Filho et al. 2007; Hoff et al. 2010).

A clear integration between the historical process of accumulation due to niche conservatism and latitudinal gradients can be translated into a lower level of diversity, when dealing with FBUs defined by allelic richness measured at a population level. Although the accumulation of neutral FBUs does not track environmental variation, the richness of FBUs at molecular level can indicates historical processes across geographic space. For instance, processes of population expansion can be evaluated by the frequency distribution of haplotypes, in which a higher allelic richness will be found in the ancestral region of the species than in the edges of the colonization wave. In this case, the molecular variation in the new regions will be nested within the ancestral regions, at least up to when current processes (new mutations randomly distributed in each of the new populations and dispersal to neighbor populations) will start to appear. The reduction of allele richness from ancestral regions is the basis of Nested Clade Analyses, widely used in population genetics and phylogeography (see Templeton 2010 for a review). This analogy opens the possibility of applying NCA to study niche conservatism when FBUs are defined as species, as well as using the partitioning of richness into turnover and nestedness components (e.g., Baselga 2010) for FBUs other than species.

It is worthwhile to note that a deeper level of integration can be achieved by using a different measure of diversity. The main idea is to define diversity not by number (richness) or turnover or FBUs at a given level, but rather by the amount of accumulated evolutionary information found in a region. These metrics have been collectively called phylogenetic diversity (PD), and can be used to measure the amount of biodiversity as well as the difference among localities or sample, analogous to beta-diversity (phylobetadiversity; see Graham \& Fine 2008). Phylogenetic diversity, for instance, can be measured by a series of metrics based on the phylogeny, the most common of which is Daniel Faith's PD, given by the sum of branch lengths linking the species found in a given region (or its beta-diversity analogous). However, PD is thus intrinsically linked with species richness, undermining its utility (i.e., see Safi et al. 2011). Helmus' et al. (2007) Phylogenetic Species Diversity (PSV) is another interesting metric that is independent of richness and can be used to establish if a given region or locality contains high diversity of species' traits and, by extension, ecosystem functions. We realize that the use of these metrics in an attempt to understand patterns and processes and to establish conservation priorities (Sechrest et al. 2002; Mace et al. 2003; Carvalho et al. 2010) is still a daunting challenge mainly because they require a complete conceptual change and a fuller understanding of the idea of the evolutionary continuum. 


\section{Distance decay in similarity}

The differentiation among geographically structured samples always played an important role for the study of molecular variation and species diversity. When dealing with ecological (or macroecological) variation, the difference among samples in terms of species composition have been called beta-diversity since the classical papers by R. H. Whittaker in the late 1950's (see Tuomisto 2010a,b for a recent review). The decay in community similarity with increasing geographic distances (e.g., Soininen et al. 2007) may be easily generalized to any level of FBUs.

For instance, under the neutral theory of biodiversity and biogeography (Hubbell, 2001), it is expected that the differences between local communities decrease exponentially with increasing geographic distance (Bell 2001). In this case, limited dispersal creates a geographic limit (range) of FBUs and thus plays a fundamental role in explaining beta diversity variation. This is empirically and theoretically analogous to the well-known pattern of genetic variation called "Isolation-By-Distance (IBD)". Originally proposed by Sewall Wright in 1943, IBD is a neutral process in which divergence among populations occurs by random variation of allele frequencies (and fixation of random mutations) and by genetic drift coupled with geographically-mediated gene flow (Epperson 2003). It is noteworthy to emphasize that, whichever the FBUs under study, the use of simple Euclidean distances to model (ecological or genetic) differentiation may not be the best choice. Indeed, the search for methods to better represent spatial contiguity or interaction is an ever-growing research agenda in ecology and evolution. For instance, resistance distance (based on linear electronic circuits) was proposed to model genetic structuring (McRae 2006), while the use of watercourse distances has been proven to be a best way to model simulated species distributions in stream networks (Landeiro et al. 2011).

The decrease in genetic similarity among population with increasing distance may be due to other processes, related to geographic range expansion, migration and eventually selection (i.e., this last one only if neutrality assumption does not hold) (Endler 1977). Sokal \& Wartenberg (1983) showed that, under IBD, the allele frequencies will display a spatial correlogram in which autocorrelation coefficients, such as Moran's $I$, tend to decrease exponentially when geographic distance increases, stabilizing at a distance equal to the mean dispersal distance per generation. This pattern, however, can appear under other processes and thus it is important to develop additional diagnosis for IBD, such as by checking if correlograms, estimated for different alleles, are similar. This needs to hold in order infer a pure neutral process despite, the fact that the frequencies of the alleles are spatially uncorrelated (see below). Likewise, when dealing with FBU at species level, it is not possible to assume a priori that there is a neutral dynamic only because distance decay in community similarity was detected. This is so because in most cases the environment is also spatially structured. Thus, it is necessary to estimate the unique roles of space (i.e., dispersal) and environment in driving community differentiation, although this task has been proven difficult to achieve (e.g., see Gilbert \& Bennett 2010 and references therein).

Because of the assumed neutrality of molecular data, the issues raised above are rarely discussed when molecular level FBUs are the focus of the study. However, recent developments in landscape genetics (Manel et al. 2004; Holderegger \& Wagner 2006; Storfer et al. 2007) are now revealing that other processes (e.g., human-induced modifications of the landscape and disruption of dispersal routes) can confound a simple test of IBD. We believe that the modeling tools widely used in ecological analyses for variance partitioning and to detect spatial discontinuities will soon start to play a major role in analyzing broad-scale patterns of genetic variation among local populations (e.g., Diniz-Filho et al. 2009). The opposite is also true, as Diniz-Filho et al. (2011) recently showed that the same protocols used to infer IBD based on spatial autocorrelation analyses can be used to test Hubbell's (2001) neutral dynamic.

\section{Spatial conservation prioritization}

Systematic Conservation Planning (SCP) (Margules \& Pressey 2000; Sarkar \& Illoldi-Rangel 2010) seeks to define and solve conservation problems by establishing a series of procedures designed to optimize conservation strategies at regional scales. For example, one goal would be to represent all species of a given group (the conservation targets) within protected areas with the smallest possible cost (Cabeza \& Moilanen 2001; Moilanen et al. 2009). The main principle underlying this approach is the idea of complementarity to minimize the redundancy among protected areas. Consequently, this principle favors rarity, an important property of FBUs at any level of the hierarchy.

SCP has been based on different FBUs, usually at species level or higher, and thus integration of methods and concepts sound promising for this field. However, although species are usually defined as the main conservation targets, it is difficult (if not impossible) to work with all taxonomic groups. This leads to the idea that surrogate groups should be used to represent processes that would also drive patterns for other groups or that higher taxa or other ecosystem surrogates (e.g., biomes, vegetation forms) should be used instead of species (e.g., Pinto et al. 2008; Grelle et al. 2010; Padial et al. 2010; Trindade-Filho \& Loyola 2011). More generally, phylogenetic diversity can be viewed as a particular form of rarity and thus can be incorporated into SCP in several ways (Sechrest et al. 2002; Rodrigues et al. 2011).

From the principles defined here, it is clear that the procedures frequently used in SCP can also be applied to optimize the conservation of interspecific targets defined at molecular level. For instance, optimization procedures can be used to find the smallest number of local populations (a 
network) that it is necessary to represent the species' genetic diversity (assuming, once again, that local populations were sampled throughout species' range) (Diniz-Filho \& Telles 2006). This can be applied both to in situ and ex situ conservation, raising interesting possibilities for applying SCP. For example, for in situ conservation, it may be desirable to add other variables as costs or weightings in the optimization procedure to prioritize populations in regions with high environmental quality, or in regions with low human influence. On the other hand, if the idea is to think about ex situ conservation, for example to organize a germplasm bank, the weighting variables may be designed to achieve goals with smaller costs in terms of sampling strategies. These two cases can be loosely related to pro-active and reactive conservation schemes (sensu Brooks et al. 2006), respectively. This is because, when organizing a germplasm bank for an endangered species, it may be important to prioritize sampling regions where there is strong human influence that can drive local populations to extinction.

Finally, it should be noted that it may be challenging to define goals and targets when applying SCP to FBUs at molecular level, mainly because the meaning of the molecular variants is not well established and, in any case, they are only surrogates for more general processes. If FBUs are defined at a very fine grain using too powerful techniques that reveal, for example, individual variation, rarity will become highly weighted and goals should be impossible to achieve. As pointed out by Diniz-Filho \& Telles (2006), one can ask how to deal with population structure of these molecular variants across different species. Alternatively, genetic diversity within a species can also be a surrogate of biodiversity in general and, indeed, some recent studies have found significant correlations between genetic and species diversity (e.g., see also Sei et al. 2009; Struebig et al. 2011).

\section{Concluding Remarks}

We envisage a continuous level of integration among different levels of the biological organization in geographically explicit ecological studies, and hopefully this can offer a research agenda for several years. We hope that the examples provided above can stimulate further applications and developments. For instance, we highlight the need for developments of optimization tools for conservation planning at genetic and population levels. Also, we think that the application of tools from statistical phylogeography might shed light to the mechanisms driving broad scale patterns of species richness, a problem pursued by ecologists and biogeographers in the last 200 years. At the same time, we foresee the continuous development of widely integrative research programs, such as the emerging fields of community phylogenetics and landscape genetics, which are emblematic examples of the power of conceptual and methodological integration of research programs that developed independently for several years. These relatively recent fields allow inferring current and past mechanisms from patterns in a new and much more convincing way.

However, our main message is that the quest for integration should not be confounded with the simple accumulation of, for instance, molecular, ecological and biogeographical data. Instead, "in praise of hard questions" (Siegfried 2005), we expect that data obtained at different levels (carefully gathered in respect to spatial extent and time scales) of the biological hierarchy, analyzed with powerful and modern analytical tools developed in several research fields, may facilitate our understanding of the astonishing biological complexity of our world. Although the task appears daunting, we believe that if we are supposed to offer reliable, scientific based advice to mitigate the biodiversity crisis we then need to integrate our efforts and recognize that most of the borders that we previously used to define the objects of our studies were rather arbitrary.

\section{Acknowledgements}

We thank Maria Lucia Lorini for the invitation to write this essay for the special issue on SIG for N\&C, and to Richard Ladle and Carlos Eduardo V. Grelle for suggestions that improved the original manuscript. Our work on macroecology, conservation biogeography, population genetics and spatial statistics have been supported by several grants from CAPES and CNPq, especially the research network GENPAC, which the main purpose is to integrate methods and concepts between macroecology and molecular ecology (MCT/CNPq proc. 564717/2010-0).

\section{References}

Avise JC, 2009. Phylogeography: retrospect and prospect. Journal of Biogeography, 36:3-15. http://dx.doi. org/10.1111/j.1365-2699.2008.02032.x

Avise JC, 2004. Molecular Markers, Natural History and Evolution. 2th ed. New York: Sinauer.

Baselga A, 2010. Partitioning the turnover and nestedness components of beta diversity. Global Ecology and Biogeography, 19:134-143. http://dx.doi. org/10.1111/j.1466-8238.2009.00490.x

Beebee TJC \& Rowe G, 2004. An introduction to molecular ecology. Oxford: Oxford University Press.

Bell G, 2001. Neutral macroecology. Science, 293:24132416. PMid:11577228. http://dx.doi.org/10.1126/ science.293.5539.2413

Bini LM, Diniz-Filho JAF, Rangel TFLVB, Bastos RP \& Pinto MP, 2006. Challenging Wallacean and Linnean shortfalls: knowledge gradients and conservation planning in a biodiversity hotspot. Diversity and Distributions, 12:475-482. http://dx.doi.org/10.1111/j.1366-9516.2006.00286.x

Brooks TM et al., 2006. Global biodiversity conservation priorities. Science, 313:58-61. PMid:16825561. http://dx.doi. org/10.1126/science.1127609 
Cabeza M \& Moilanen A, 2001. Design of reserve networks and the persistence of biodiversity. Trends in Ecology \& Evolution, 16:242-248. http://dx.doi.org/10.1016/ S0169-5347(01)02125-5

Crisp MD et al., 2009. Phylogenetic biome conservatism on a global scale. Nature, 458:754-756. PMid:19219025. http:// dx.doi.org/10.1038/nature07764

Carvalho RA, Cianciaruso MV, Trindade-Filho J, Sagnori MD \& Loyola RD, 2010. Drafting a blueprint of functional and phylogenetic diversity conservation for Brazilian Cerrado. Natureza \& Conservação, 8:171-176. http://dx.doi. org/10.4322/natcon.00802011

Decaëns T, 2010. Macroecological patterns in soil communities. Global Ecology and Biogeography, 19:287-302. http://dx.doi. org/10.1111/j.1466-8238.2009.00517.x

Dequiedt S et al., 2011. Biogeographic patterns of soil molecular microbial biomass as influenced by soil characteristics and management. Global Ecology and Biogeography, 20:641-652. http://dx.doi.org/10.1111/j.1466-8238.2010.00628.x

Diniz-Filho JAF \& Telles MPC, 2002. Spatial autocorrelation analysis and the identification of operational units for conservation in continuous populations. Conservation Biology, 16:924-935. http://dx.doi. org/10.1046/j.1523-1739.2002.00295.x

Diniz-Filho JAF \& Telles MPC, 2006. Optimization procedures for establishing reserve networks for biodiversity conservation taking into account population genetic structure. Genetics and Molecular Biology, 29:207-214. http://dx.doi.org/10.1590/ S1415-47572006000200004

Diniz-Filho JAF, Rangel TFLVB, Bini LM \& Hawkins BA, 2007. Macroevolutionary dynamics in environmental space and the latitudinal diversity gradient in New World birds. Proceedings of Royal Society B, 274:43-52. PMid:17018430. PMCid:1679877. http://dx.doi.org/10.1098/rspb.2006.3712

Diniz-Filho JAF et al., 2008. Mapping the evolutionary twilight zone: molecular markers, populations and geography. Journal of Biogeography, 35:753-763. http://dx.doi. org/10.1111/j.1365-2699.2008.01912.x

Diniz-Filho JAF, Nabout JC, Telles MPC, Soares TN \& Rangel TFLVB, 2009. A review of techniques for spatial modeling in geographical, conservation and landscape genetics. Genetics and Molecular Biology, 32:203-211. PMid:21637669. PMCid:3036944. http://dx.doi.org/10.1590/ S1415-47572009000200001

Diniz-Filho JAF et al., 2011. Spatial autocorrelation analysis allows disentangling the balance between neutral and niche processes in metacommunities. Oikos (in press).

Endler JA, 1977. Geographic variation, speciation, and clines. Princeton: Princeton University press.

Epperson BK, 2003. Geographical Genetics. Princeton: Princeton Univ. Press.

Freedman AH, Thomassen HA, Buermann W \& Smith TB, 2010. Genomic signals of diversification along ecological gradients in a tropical lizard. Molecular Ecology, 19:3733-3788. PMid:20618893. http://dx.doi. org/10.1111/j.1365-294X.2010.04684.x
Gaston KJ, 1996. Biodiversity: a biology of numbers and differences. New York: Blackwell.

Gilbert B \& Bennett JR, 2010. Partitioning variation in ecological communities: do the numbers add up? Journal of Applied Ecology, 47:1071-1082. http://dx.doi. org/10.1111/j.1365-2664.2010.01861.x

Graham CH \& Fine PVA, 2008. Phylogenetic beta diversity: linking ecological and evolutionary processes across space and time. Ecology Letters, 11:1265-1277. http://dx.doi. org/10.1111/j.1461-0248.2008.01256.x

Graham CH et al., 2004. New developments in museum-based informatics and applications in biodiversity analysis. Trends in Ecology and Evolution, 19:497-503. http://dx.doi. org/10.1016/j.tree.2004.07.006

Grelle CEV, Lorini MA \& Pinto MP, 2010. Reserve selection based on vegetation in the brazilian atlantic forest. Natureza \& Conservação, 8:46-53. http://dx.doi.org/10.4322/ natcon.00801007

Guisan A \& Rahbek C, 2011. SESAM - a new framework integrating macroecological and species distribution models for predicting spatio-temporal patterns of species assemblages. Journal of Biogeography, 38:1433-1444. http:// dx.doi.org/10.1111/j.1365-2699.2011.02550.x

Hawkins BA, 2001. Ecology oldest pattern? Trends in Ecology and Evolution, 16:470. http://dx.doi.org/10.1016/ S0169-5347(01)02197-8

Hawkins BA et al., 2003. Energy, water, and broad-scale geographic patterns of species richness. Ecology, 84:31053117. http://dx.doi.org/10.1890/03-8006

Hawkins BA et al., 2006. Post-eocene climate change, niche conservatism, and the latitudinal diversity gradient of New World birds. Journal of Biogeography, 33:770-780. http:// dx.doi.org/10.1111/j.1365-2699.2006.01452.x

Hawkins BA et al., 2007. Climate, Niche Conservatism, and the Global Bird Diversity Gradient. American Naturalist, 170:1627. http://dx.doi.org/10.1086/519009

Helmus MR et al., 2007. Phylogenetic measures of biodiversity. American Naturalist, 169:E68-E83. http://dx.doi. org/10.1086/511334

Hof C, Rahbek C \& Araújo MB, 2010. Phylogenetic signals in the climatic niches of world's amphibians. Ecography, 33:242-250.

Holderegger R \& Wagner HH, 2006. A brief guide to landscape genetics. Landscape Ecology, 21:793-796. http://dx.doi. org/10.1007/s10980-005-6058-6

Hubbell SP, 2001. The Unified Neutral Theory of Biodiversity and Biogeography. Princeton: Princeton Univ. Press.

Isaac NJB, Mallet J \& Mace GM, 2004. Taxonomic inflation: its influence on macroecology and conservation. Trends in Ecology and Evolution, 19:464-469. http://dx.doi. org/10.1016/j.tree.2004.06.004

Keller I, Taverna A \& Seehausen O, 2011. Evidence of neutral and adaptive genetic divergence between European trout populations sampled along altitudinal gradients. Molecular Ecology, 20:1888-1904. http://dx.doi. org/10.1111/j.1365-294X.2011.05067.x 
Kozak KH, Graham CH \& Wiens JJ, 2008. Integrating GIS-based environmental data into evolutionary biology. Trends in Ecology and Evolution, 23:141-148. http://dx.doi. org/10.1016/j.tree.2008.02.001

Ladle RJ \& Whittaker RJ, 2011. Conservation Biogeography. Oxford: Wiley-Blackwell. http://dx.doi. org/10.1002/9781444390001

Landeiro VL \& Magnusson WE, 2011. The geometry of spatial analysis: implications for conservation biologists. Natureza \& Conservação, 9:7-20. http://dx.doi.org/10.4322/ natcon.2011.002

Landeiro VL et al., 2011. Spatial eigenfunction analyses in stream networks: do watercourse and overland distances produce different results? Freshwater Biology, 56:1184-1192. http://dx.doi.org/10.1111/j.1365-2427.2010.02563.x

Loyola RD et al., 2011. Towards innovative integratred approaches for the conservation of mammals. Natureza \& Conservação, 9:1-6. http://dx.doi.org/10.4322/ natcon.2011.001

Mace G, Gittleman JL \& Purvis A, 2003. Preserving the tree of life. Science, 13:1707-1709. http://dx.doi.org/10.1126/ science. 1085510

McLachLan AJ \& Ladle R, 2011. Barriers to adaptive reasoning in community ecology. Biological Reviews, 86:543-548.

McRae BH, 2006. Isolation by resistance. Evolution, 60:1551-1561.

Manel S et al., 2003. Landscape genetics: combining landscape ecology and population genetics. Trends in Ecology and Evolution, 18:189-197. http://dx.doi.org/10.1016/ S0169-5347(03)00008-9

Margules CR \& Pressey RL, 2000. Systematic conservation planning. Nature, 405:243-253. http://dx.doi. org/10.1038/35012251

Mittelbach GG et al., 2007. Evolution and the latitudinal diversity gradient: speciation, extinction and biogeography. Ecology Letters, 10:315-331. http://dx.doi. org/10.1111/j.1461-0248.2007.01020.x

Moilanen A, Wilson KA \& Possingham H, 2009. Spatial Conservation Prioritization: quantitative methods and computational tools. Oxford: Oxford University Press.

Padial AA et al., 2010. Predicting patterns of beta diversity in terrestrial vertebrates using phyisographic classifications in Brazilian Cerrado. Natureza \& Conservação, 8:127-132. http://dx.doi.org/10.4322/natcon.00802004

Peres-Neto PR, 2006. A unified strategy for estimating and controlling spatial, temporal and phylogenetic autocorrelation in ecological models. Oecologia Brasiliensis, 10:105-119. http://dx.doi.org/10.4257/oeco.2006.1001.07

Pimm S et al., 2010. How many endangered species remain to be discovered in Brazil? Natureza \& Conservação, 8:71-77. http://dx.doi.org/10.4322/natcon.00801011

Pinto MP et al., 2008. Biodiversity surrogate groups and conservation priority áreas: birds of the Brazilian Cerrado. Diversity and Distributions, 14:78-86. http://dx.doi. $\operatorname{org} / 10.1111 / \mathrm{j} .1472-4642.2007 .00421 . \mathrm{x}$
Rangel, TFLVB \& Diniz-Filho JAF, 2005. An evolutionary tolerance model explaining spatial patterns in species richness under environmental gradients and geometrics constraints. Ecography, 28:253-263. http://dx.doi. org/10.1111/j.0906-7590.2005.04038.x

Rangel TFLVB, Diniz-Filho JAF \& Colwell RK, 2007. Species richness and evolutionary niche dynamics: a spatial pattern-oriented simulation experiment. American Naturalist, 170:602-616. http://dx.doi.org/10.1086/521315

Rodrigues ASL et al., 2011. Complete, accurate, mammalian phylogenies aid conservation planning, but not much. Philosophical Transactions of Royal Society B, 366:2652-2660. http://dx.doi.org/10.1098/rstb.2011.0104

Safi K et al., 2011. Understanding global patterns of mammalian functional and phylogenetic diversity. Philosophical Transactions of Royal Society B, 366:2536-2544. http:// dx.doi.org/10.1098/rstb.2011.0024

Sarkar S \& Illoldi-Rangel P, 2010. Systematic conservation planning: an updated protocol. Natureza \& Conservação, 8:1926. http://dx.doi.org/10.4322/natcon.00801003

Sechrest W et al., 2002. Hotspots and the conservation of evolutionary history. Proceedings of the National Academy of Sciences, 99:2067-2071. http://dx.doi.org/10.1073/ pnas. 251680798

Sei M, Lang BK \& Berg D, 2009. Genetic and community similarities are correlated in endemic-rich springs of the northern Chihuanuan desert. Global Ecology and Biogeography, 18:192-201. http://dx.doi. org/10.1111/j.1466-8238.2008.00436.x

Siegfried T, 2005. In praise of hard questions. Science, 309(5731):76-77. http://dx.doi.org/10.1126/ science.309.5731.76

Soininen J et al., 2007. The distance decay of similarity in ecological communities. Ecography, 30:3-12.

Sokal RR \& Wartenberg DE, 1983. A test of spatial autocorrelation analysis using an isolation-by-distance model. Genetics, 105:219-237.

Storfer A et al., 2007. Putting the 'landscape' in landscape genetics. Heredity, 98:128-142. http://dx.doi.org/10.1038/ sj.hdy. 6800917

Storfer A et al., 2010. Landscape genetics: where are we now? Molecular Ecology, 19:3496-3514. http://dx.doi. org/10.1111/j.1365-294X.2010.04691.x

Stone GN, Nee S \& Felsenstein J, 2011.Controlling for non-independence in comparative analysis of patterns across populations within species. Philosophical Transactions of Royal Society B, 366:1410-1424. http://dx.doi.org/10.1098/ rstb.2010.0311

Struebig MJ et al., 2011. Parallel declines in species and genetic diversity in tropical forest fragments. Ecology Letters, 14:582 590. http://dx.doi.org/10.1111/j.1461-0248.2011.01623.x

Templeton AR, 2010. The diverse applications of cladistic analysis of molecular evolution, with special reference to nested clade analysis. International Journal of Molecular Evolution, 11:124-139. 
Terribile LC et al., 2009. Richness patterns, species distributions and the principle of extreme deconstruction. Global Ecology and Biogeography, 18:123-136. http://dx.doi. org/10.1111/j.1466-8238.2008.00440.x

Thomassen HA et al., 2011. Mapping evolutionary processes: a multi-taxa approach to conservation prioritization. Evolutionary Applications, 4:397-413. http://dx.doi. org/10.1111/j.1752-4571.2010.00172.x

Tobler W, 1970. A computer movie simulating urban growth in the Detroit region. Economic Geography, 46: 234-240.

Trindade-Filho J \& Loyola RD, 2011. Performance and consistency of indicator groups in two Biodiversity Hotspots. PLoS ONE, 6:e19746v. http://dx.doi.org/10.1371/journal. pone. 0019746

Tuomisto H, 2010a. A diversity of beta diversities: straightening up a concept gone awry. Part 1 . Defining beta diversity as a function of alpha and gamma diversity. Ecography, 33:2-22. http://dx.doi.org/10.1111/j.1600-0587.2009.05880.x

Tuomisto H, 2010b. A diversity of beta diversities: straightening up a concept gone awry. Part 2. Quantifying beta diversity and related phenomena. Ecography, 33:23-45. http://dx.doi. org/10.1111/j.1600-0587.2009.06148.x

Vamosi SM et al., 2009. Emerging patterns in the community analysis of phylogenetic community structure. Molecular Ecology, 38:572-592. http://dx.doi. org/10.1111/j.1365-294X.2008.04001.x

Whittaker RJ et al., 2005. Conservation biogeography: assessment and prospect. Diversity and Distributions, 11:3-23. http:// dx.doi.org/10.1111/j.1366-9516.2005.00143.x

Webb CO et al., 2002. Phylogenies and community ecology. Annual Review of Ecology and Systematics, 33:475-505. http://dx.doi.org/10.1146/annurev.ecolsys.33.010802.150448

Wiens JJ \& Donoghue MJ. 2004. Historical biogeography, ecology and species richness. Trends in Ecology and Evolution, 19: 639-644. http://dx.doi.org/10.1016/j. tree.2004.09.011

Wiens JJ et al., 2010. Niche conservatism as an emerging principle in ecology and conservation biology. Ecology Letters, 13:13101324. http://dx.doi.org/10.1111/j.1461-0248.2010.01515.x

Yarrow MM \& Salthe SN, 2008. Ecological boundaries in the context of hierarchy theory. BioSystems, 92:233-244. http:// dx.doi.org/10.1016/j.biosystems.2008.03.001

Received: September 2011

First Decision: October 2011 Accepted: November 2011 